\title{
Modeling for Surfactant-Enhanced Groundwater Remediation Processes at DNAPLs-Contaminated Sites
}

\author{
L. Liu* \\ Department of Civil Engineering, Dalhousie University, Halifax, NS B3J 1Z1, Canada
}

\begin{abstract}
In this study, a numerical modeling technique for simulating surfactant-enhanced groundwater remediation processes is introduced. The model could not only examine the physicochemical behaviour of a multiphase system due to surfactant injection through considering balance equations for all phases, but also explain the solubilization and mobilization mechanisms for removing entrapped residual DNAPL due to introduction of surfactant solutions. The model is applied to a hypothetical PCE-contaminated site for simulating the surfactant-flushing process. The application indicates that, given some approximate information of initial PCE distribution and layering, surfactant-enhanced remediation can be simulated by the model to a reasonable degree of certainty. The modeling results show that the surfactant has the significant potential to improve remediation efficiency, reduce remediation time, and lower down remediation costs in comparison with conventional pump-and-treat remediation measure. This study demonstrates the model's capability in simulating the remediation processes and effectiveness in interpreting surfactant enhancement effect. It is indicated that modeling studies could not only help gain insights of the remediation processes but also provide scientific bases for decision and design of site-specific remediation plans.
\end{abstract}

Keywords: Contaminant, groundwater, NAPLs, remediation, simulation model, surfactant

\section{Introduction}

Groundwater is one of the most important water supply sources in the world. In the North America, it is estimated that approximately $50 \%$ of the population and more than $90 \%$ of rural residents use groundwater as their primary source of domestic drinking water, and about $34 \%$ of the irrigation water in the agriculture comes from groundwater (USGS, 1990). In addition, about $30 \%$ of river and stream flow is contributed by groundwater (USEPA, 1991). It has been well recognized that in the coming decades, groundwater will continue to grow in importance as a vital lift-support need for human beings.

Unfortunately, over the last thirty years groundwater contamination concerns have been emerging as one of the major environmental and health issues (NRC, 1994). Groundwater is threatened by past and present contaminants from sources such as mining, agriculture, landfills, and industrial activities. After being discharged, the pollutants can migrate through on-site soil, and contaminate groundwater bodies, leading to a variety of adverse impacts and damages to ecosystem, human heath and for the relevant industries themselves. For example, the past practices in the U.S. indicate that groundwater cleanup systems often cost millions of dollars at a single site. There exists more than 217,000 contaminated sites in the U.S. that need to be restored under current federal and state regula-

\footnotetext{
* Corresponding author: Lei.Liu@Dal.Ca
}

tions, with a cost of over $\$ 187$ billion (USEPA, 1996). Consequently, it becomes very important for both governments and industries to utilize effective remediation technologies with sound environmental and soico-economic efficiencies.

Of the organic contaminants which have been detected in groundwater, dense non-aqueous phase liquids (DNAPLs) such as chlorinated solvents are one class of NAPL contaminants with particular concerns due to their large densities, high interfacial tension, and low solubilities. They tend to migrate vertically under gravity forces, displacing water within the saturated zone, and spread laterally and deeply within a formation. As NAPLs migrate through a porous formation, a portion of the organic liquid is entrapped within the pores, which may occupy $5 \%$ to $40 \%$ of the pore volume. It is generally recognized that the prevalence of non-aqueous phase liquids (NAPLs) in subsurface is a significant impediment to groundwater restoration.

In order to understand the migration and fate of NAPLs in aquifer, previously, considerable research efforts have been placed on the development of mathematical models through using transport phenomena and basic conservation principles to address groundwater flow and NAPLs transport, and examining the behavior and effectiveness of various cleanup measures (Faust, 1985; Abriola and Pinder, 1985a, b; Corapcioglu and Baehr, 1987; Kuppasamy et al., 1987; Faust et al., 1989; Kaluarachchi and Parker, 1989; Kueper and Frind, 1991; Falta et al., 1992a, b; Sleep and Sykes, 1993; Huyakorn et al., 1994; Pandy et al., 1995; de Blanc, 1996; Katyal, 1997). All these models include a NAPLs contaminant mass balance, 
water and air in the subsurface and simplifying assumptions with respect to phase presence and dimensionality.

In the last two decades, a number of remediation techniques have been developed for cleaning up the DNAPLscontaminated sites. At most of contaminated sites, because of the slow rate of contaminant movement in the subsurface environment, and the complex interaction between contaminants and geological surroundings, conventional pumping-and-treat remedial measures can last decades and cost hundreds of millions of dollars and have proven to be an ineffective and costly approach to groundwater remediation especially when chlorinated solvents are present (Mackay and Cherry, 1989; Haley et al., 1991). Surfactant-enhanced groundwater remediation (SEGR) is currently under active research and development as a promising alternative technology for which can avoid at lease some of the problems and limitations of many other remediation methods (Fountain and Hodge, 1992; Fountain et al., 1991, 1997; West and Harwell, 1992; Pennell and Abriola, 1997). In general, these methods involve the injection of solutions with surfactant concentrations sufficient to cause the formation of colloidal aggregates of surfactant molecules, known as micelles, which are responsible for the enhanced solubilization of DNAPLs in the aqueous phase microemulsion. The surfactant also tends to lower the interfacial tension between the organic and aqueous phases, possibly resulting in mobilization of the entrapped DNAPLs. Solubilization and mobilization are the two mechanisms by which surfactant can enhance the removal of DNAPLs from saturated aquifers (Pennell et al., 1994).

Literature survey shows that aqueous surfactant solutions have been used in both laboratory and field-scale remediation studies in the past 2 decades, and there are some efforts emphasizing on mathematical modeling of surfactant enhanced groundwater remediation processes. They have focused primarily on single-phase (aqueous) flow, assuming that recovery of entrapped residual is through promotion of micellar solubilization. For example, Wilson (1989) and Wilson and Clarke (1991) considered adsorption of the surfactant and solubilization of the contaminant in examining surfactant remediation at the field and laboratory scale when developing a two-dimensional areal, single-phase flow model. Abriola et al. (1993) presented a one-dimensional numerical model to simulate surfactant-enhanced solubilization of NAPL in porous media subject to nonequilibrium mass transfer between NAPL and an aqueous surfactant solution, with special emphasis on rate-limited mass transfer. Mason and Kueper (1996) presented a similar one-dimensional model where the nonequilibrium mass transfer term accounts for high nonwetting phase saturations found in NAPL pools. The developed model was compared to laboratory column experiments involving the solubilization of pooled PCE (Perchloroethylene or tetrachloroethylene).

In general, any numerical model that simulates phase migration subject to mass transfer between phases can be used to simulate surfactant flushing of aquifer provided that appropriate constitutive relationships are incorporated. How- ever, simulation of SEGR measures may involve complex multiphase systems in which a significant mass of surfactant is added to this system and is subject to bulk movement and distribution among the phase present. On the one hand, surfactant injection can significantly affect many aspects of the physicochemical behaviour of a multiphase system since additional consideration of balance equations for any additional phase(s) is required. On the other hand, solubilization is only one of the two mechanisms acting to remove entrapped residuals under introduction of an aqueous surfactant solution. The surfactant can also potentially promote mobilization of the NAPL as a separate phase through reducing the interfacial tension (IFT) between organic and aqueous phases. Thus, a general SEGR modeling approach must necessarily be multiphase, taking into consideration the complexities created by IFT reduction and phase behavior (Datta Gupta et al., 1986; Saad et al., 1990; Bhuyan et al., 1990; Liu, 1993; Delshad and Pope, 1989). In addition, the modeling approach should be multidimensional and permit heterogeneous distributions of properties to appropriately assess the conditions present at the field scale.

In this study, a comprehensive and practical tool for simulating surfactant-enhanced groundwater remediation process is presented and applied to explore the potential performance of this technology, to improve our understanding of process mechanisms, and to identify alternative strategies and approaches of cleanup actions. The simulator incorporates nonequilibrium mass transfer, constant potential surface boundary, and primary drainage capillary pressure and relative permeability into a general framework. The model is applied to a hypothetical test site for illustrating the role of modeling approaches in SEGR design, the accomplishment of modeling process, the required information, and expected remediation efficiency. This study describes preliminary scoping simulations of the surfactant flushing process at the test site to demonstrate the capability of the model. Due to the lack of experimental information for verifying modeling results, the simulations presented in this study are confined to a relatively simple and idealized aquifer domain and to what appear to be the most important design considerations. Meanwhile, all simulations are restricted to the saturated zone, to one typical DNAPL (PCE in this study), and to one typical surfactant mixture. When applying this technology to practical implementation, more additional modeling and experimental efforts (such as surfactant screening, phase behavior, sorption, column flushing experiments, and so on) should be undertaken to answer the numerous and complex relevant questions.

\section{Model Conceptualization and Formulation}

The model presented below is a three-dimensional, multiphase, multicomponent, compositional simulator capable of modeling flow and mass transportation in aquifers undergoing remediation, which was developed by the Petroleum and Geosystems Engineering Center at the University of Texas at 
Austin (Delshad et al., 1996). It can model up to four phases (aqueous, gas, NAPL, microemulsion), up to 18 components (including water, PCE, and surfactant), and has the capability to simulate enhanced solubilization and increased mobilization resulting from surfactant injection. In this modeling study, the microemulsion phase was an aqueous solution containing water, surfactant, and dissolved PCE. This model is based on two balance equations: (1) the mass-balance equation for each species; and (2) the pressure equation for both aqueous phase pressure and other phases.

\subsection{Mass Conservation Equation}

The continuity of mass for each component in association with Darcy's law is expressed below in terms of overall of this component per unit pore volume as (Brown et al., 1994). The assumptions imposed include local thermodynamic equilibrium except for tracers and dissolution of organic component, immobile solid phases, slightly compressible soil and fluids, Fickian dispersion, ideal mixing, and Darcy's law. The boundary conditions are no flow and no dispersive flux across the impermeable boundaries (Delshad et al., 1996; de Blanc, 1996).

$\frac{\partial}{\partial t}\left(\phi \tilde{C}_{k} \rho_{k}\right)+\vec{\nabla} \cdot\left[\sum_{l=1}^{n_{p}} \rho_{k}\left(C_{k l} \vec{u}_{l}-\phi S_{l} \overrightarrow{\tilde{D}}_{k l} \cdot \vec{\nabla} C_{k l}\right)\right]=R_{k}$

where $k=$ component index; $l=$ phase index; $\phi=$ porosity; $C_{k}$ $=$ overall concentration of component $k$ (volume of component $k$ per unit pore volume); $\rho_{k}=$ density of component $k$ $\left[\mathrm{ML}^{-3}\right] ; n_{p}=$ number of phases; $C_{k l}=$ concentration of component $\mathrm{k}$ in phase $l$ (volume fraction); $\vec{u}_{l}=$ Darcy velocity of phase $l\left[\mathrm{LT}^{-1}\right] ; S_{l}=$ the saturation of phase $l$ (volume of phase $l$ per volume of pores); $R_{k}=$ total source/sink term for component $\mathrm{k}$ (volume of component $k$ per unit volume of porous media per unit time).

The overall concentration $\tilde{C}_{k}$ is the volume of component $k$ summed over all phases, including the adsorbed phase:

$\tilde{C}_{k}=\left(1-\sum_{k=1}^{n_{c v}} \hat{C}_{k}\right) \sum_{l=1}^{n_{p}} S_{l} C_{k l}+\hat{C}_{k}$ for $k=1, \ldots, n_{c v}$

where $\hat{C}_{k}=$ the adsorbed concentration of component $k$ (volume of component $k$ per unit pore volume); $n_{c v}=$ the number of volume-occupying components (including gas, NAPL, water, etc.). With ideal mixing and small and constant compressibilities $C_{k}^{0}$ :

$\rho_{k}=1+C_{k}^{0}\left(P_{R}-P_{R 0}\right)$

where $P_{R}=$ reference phase pressure; $P_{R 0}=$ reference pressure.

The dispersive flux is assumed to have a Fickian dispersion form:
$\overrightarrow{\tilde{D}}_{k l}=\phi S_{l} \overrightarrow{\vec{K}}_{k l} \cdot \vec{\nabla} C_{k l}$

where $\overrightarrow{\vec{K}}_{k l}$ is the dispersion tensor, which is given by Bear (1979):

$\overrightarrow{\bar{K}}_{k l i j}=\frac{D_{m, k l}}{\tau} \delta_{i j}+\frac{\alpha_{T l}}{\phi S_{l}}\left|\vec{u}_{l}\right| \delta_{i j}+\frac{\left(\alpha_{L l}-\alpha_{T l}\right)}{\phi S_{l}} \frac{u_{l i} u_{l j}}{\left|\vec{u}_{l}\right|}$

where $\tau=$ tortuosity (defined with a value greater than 1 ); $D_{m, k l}=$ molecular diffusion coefficient of component $\mathrm{k}$ in phase $1\left[\mathrm{~L}^{2} \mathrm{~T}^{-1}\right] ; \delta_{i j}=$ Kronecker delta function; $\alpha_{L l}, \alpha_{T l}=$ longitudinal and transverse dispersivities, respectively [L]; $u_{l i}$, $u_{l j}=$ components of Darcy velocity in directions $i$ and $j$, respectively $\left[\mathrm{LT}^{-1}\right] ;\left|\vec{u}_{l}\right|=$ magnitude of the vector flux for phase $1\left[\mathrm{LT}^{-1}\right]$.

Term $\left|\vec{u}_{l}\right|$ can be calculated by:

$\left|\vec{u}_{l}\right|=\sqrt{\left(u_{x l}\right)^{2}+\left(u_{y l}\right)^{2}+\left(u_{z l}\right)^{2}}$

The phase flux is calculated from the multiphase form of Darcy's law:

$\vec{u}_{l}=-\frac{k_{r l} \overrightarrow{\vec{k}}}{\mu_{l}} \cdot\left(\vec{\nabla} P_{l}-\rho_{l} g \vec{\nabla} \mathrm{z}\right)$

where $k_{r l}=$ relative permeability of porous medium to phase $l$; $\vec{k}=$ intrinsic permeability tensor $\left[\mathrm{L}^{2}\right] ; \mu_{l}=$ viscosity of phase $l$ $\left[\mathrm{ML}^{-2} \mathrm{~T}^{-1}\right] ; \rho_{l}=$ density of phase $l\left[\mathrm{ML}^{-3}\right] ; g=$ acceleration of gravity $\left[\mathrm{LT}^{-2}\right] ; z=$ vertical distance, defined as positive downward $[\mathrm{L}] ; P_{l}=$ pressure of phase $l\left[\mathrm{ML}^{-1} \mathrm{~T}^{-2}\right]$.

The formulation method expressed in Equation (1a) represents a compositional approach to simulate multiphase flow in the subsurface, in which the conservation equations are developed by summing the mass balance equations for each constituent over all of the phases (Abriola and Pinder 1989). The source/sink term $R_{k}$ in Equation (1a) include all the changes in volume of component $k$ from reaction and well injection/production.

When a NAPL component dissolves in water, its concentration in ground water can reach its solubility (equilibrium mass transfer) but often is much lower than the solubility due to a rate-limited mass transfer. This model allows for both equilibrium and non-equilibrium mass transfer for multiple organic NAPL.

\subsection{Pressure Equation}

The pressure equation is developed by summing the mass balance equations over all volume-occupying components, substituting the Darcy's law for the phase flux terms, using the definition of capillary, and noting that $\sum_{k=1}^{n_{n}} C_{k l}=1$. The pressure equation in terms of reference phase pressure (water 
phase pressure) is:

$$
\begin{aligned}
\phi C_{t} \frac{\partial P_{w}}{\partial t}+\vec{\nabla} \cdot \overrightarrow{\vec{k}} \cdot \lambda_{r T_{c}} \vec{\nabla} P_{w} & =-\vec{\nabla} \cdot \sum_{l=1}^{n_{p}} \overrightarrow{\vec{k}} \cdot \lambda_{r l c} \vec{\nabla} z \\
& +\vec{\nabla} \cdot \sum_{l=1}^{n_{p}} \overrightarrow{\vec{k}} \cdot \lambda_{r l c} \vec{\nabla} P_{c l w}+\sum_{k=1}^{n_{c v}} Q_{k}
\end{aligned}
$$

where $C_{t}=$ total compressibility (the volume weighted sum of matrix and component compressibilities); $P_{w}=$ water phase pressure; $\lambda_{\text {rlc }}=$ relative mobility; $\lambda_{r T c}=$ total relative mobility; $P_{c l w}=$ capillary pressure difference between phase $l$ and the water phase; $Q_{k}=$ injection/production rate for component $k$ per bulk volume.

The term $\lambda_{\text {rlc }}$ and $\lambda_{\text {rTc }}$ can be defined as:

$\lambda_{r l c}=\frac{k_{r l}}{\mu_{l}} \sum_{k=1}^{n_{c v}} \rho_{k} C_{k l}$

and

$\lambda_{r T_{c}}=\sum_{l=1}^{n_{p}} \lambda_{r l c}$

The term $C_{t}$, the total compressibility, can be defined as:

$C_{t}=C_{r}+\sum_{k=1}^{n_{c \nu}} C_{k}^{o} \tilde{C}_{k}$

where $C_{r}=$ soil matrix compressibility; $C_{k}^{o}=$ compressibility of component $k$.

\subsection{Well Models}

In this study, injection and production wells are considered as source and sink terms in the flow equations. Wells can be completed vertically in several layers of the aquifer or horizontally with any length and can be controlled according to pressure or rate constraints. The well model is based on the formulation by Peaceman (1983) and Babu and Odeh (1989). The aquifer boundaries are treated as either constant-potential or closed surfaces.

\subsection{Solution Technique}

The above groundwater flow and contaminant transport model consists of a set of partial differential equations. Numerical solution of these equations requires that values of the dependent variables are obtained at a finite number of discrete points in space and time. The solution domain now becomes a set of discrete grid blocks (nodes) and the value of the dependent variable at each node is related to the neighboring nodes through an algebraic equation. This algebraic equation is an approximation of the differential equation, defined at every node of the domain. The numerical simulator then solves the set of algebraic equations in space and time.

The solution method used for the flow system in the model is analogous to the implicit pressure-explicit saturation method, which is well-established in the petroleum engineering literature (Abriola and Pinder, 1989). The flow equations are solved using a block-centred finite-difference scheme. The pressure equation is firstly solved implicitly using a Jacobi conjugate gradient solver to yield the water phase pressure in all grid blocks (nodes). Once the water phase pressure is known, capillary pressures from the previous time step are used to determine the pressure of the other phases in each grid block. Darcy's law is then used to determine the phase velocities, and the mass conservation equations are solved explicitly to yield the concentration of each component in each grid block. The phase concentrations and saturations are determined through flash calculations (Wang and Barker, 1997), and the new capillary pressures are determined from the new saturations. This procedure is then repeated for each time step until the simulation ends.

\section{Overview of the Hypothetical Test Site}

The above multiphase compositional simulator was used to model the migration and surfactant-enhanced remediation of PCE at the hypothetical test site. The simulation area is considered as a pseudo-3-dimensional domain. The area is $100 \times 25 \mathrm{~m}^{2}$ with a depth of $15 \mathrm{~m}$ (Figure 1). Vertically, the simulation domain is discretized into 10 layers, and the distance between each two layers is $1 \mathrm{~m}$. Each layer has an area of $100 \times 25 \mathrm{~m}^{2}$ and is discretized into $100 \times 1$ grid blocks. Each grid block has dimensions of 1, 25, and $1 \mathrm{~m}$ for $\mathrm{x}, \mathrm{y}$, and $\mathrm{z}$ directions, respectively. PCE release is at the center of the top layer.

The simulation domain at the site is a water-saturated layered sand, and its top and bottom layers are clay aquitard. An injection-production system with two surfactant injection wells and one production well are installed, and the injection and production wells penetrate the entire depth of the sandy aquifer. As depicted in Figure 1, zero-flow boundary conditions are enforced at the top and bottom of the simulation domain, and first-type boundary conditions at the left and right boundaries, creating a flow from right to left under a low hydraulic gradient $\left(10^{-6} \mathrm{~m} / \mathrm{m}\right)$.

Physical properties of the simulation aquifer have been assumed according to references and literatures and are presented in Table 1 (Sudicky, 1986; Mackay et al., 1986; Kueper, 1989). The simulation domain is located in the saturated zone of the aquifer with an assumed thickness of 15 $\mathrm{m}$. The porosity is assumed spatially and uniformly distributed within the aquifer with a constant value of 0.36 . The permeability within the simulation domain is assumed to be constant with a value of $9.0 \times 10^{-12} \mathrm{~m}^{2}$, indicating that the study aquifer is a relatively homogeneously natural sandy aquifer. For the sandy aquifer, the longitudinal dispersivity value of $8.0 \mathrm{~m}$ and the transverse dispersivity value of $0.8 \mathrm{~m}$ 


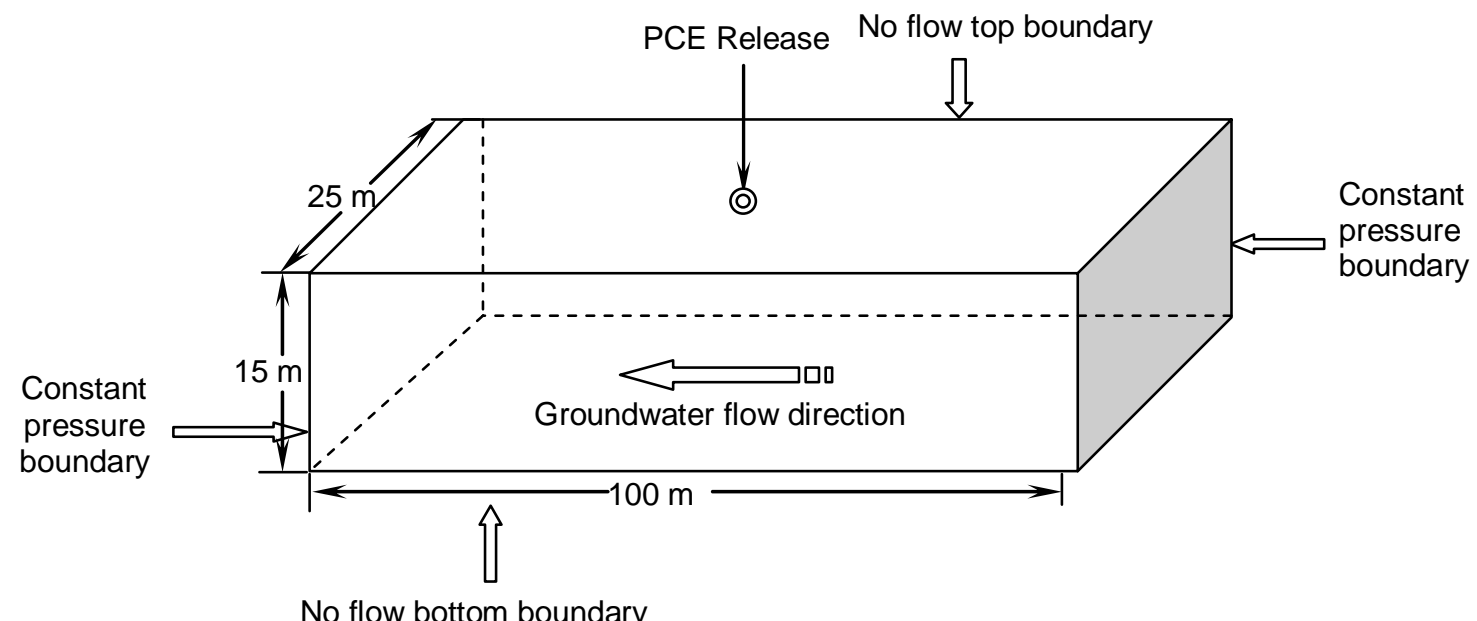

Figure 1. The simulation domain at the test site.

are selected in the simulation. Meanwhile, a small natural horizontal hydraulic gradient of $0.00375 \mathrm{~m} / \mathrm{m}$ is employed in all simulation. This gradient is created by applying constant potential conditions at the vertical right and left boundaries of the domain (Figure 1). In the absence of injection and production wells, this gradient drives both groundwater and PCE flows to the downgradient direction. In this study, the upper and bottom boundaries are treated as no flow boundaries. In addition, compressibilities of fluid and soil matrix are neglected.

Table 1. Physical Properties of the Simulation Aquifer

\begin{tabular}{ll}
\hline Property & Value \\
\hline Simulation aquifer thickness & $15 \mathrm{~m}$ \\
Porosity & 0.36 \\
Permeability & $9.0 \times 10^{-12} \mathrm{~m}^{2}$ \\
Hydraulic gradient & $0.00375 \mathrm{~m} / \mathrm{m}$ \\
Longitudinal dispersivity & $8.0 \mathrm{~m}$ \\
Transverse dispersivity & $0.8 \mathrm{~m}$ \\
\hline
\end{tabular}

Table 2 summarizes the chemical and capillary parameters of PCE used in the simulations. An anionic surfactant mixture of sodium diamyl and dioctyl sulfosuccinates is used. This sulfonate mixture has low toxicity, favorable phase behavior and performance in PCE column-flushing experiments (Pennell et al., 1994). It could reach nearly 300-fold enhancement of the aqueous solubility of PCE. The resulting equilibrium mixture of PCE and surfactant solution forms a type I microemulsion system, which is attractive for solubilization applications.

Model grid block parameters and boundary and initial conditions employed in the simulation are given in Table 3.
The test aquifer is assumed to be perfectly horizontal with impervous lower and upper boundaries (as shown in Figure 1). An initial pressure distribution is generated based on the imposed pressure gradient, the assumption of vertical equilibrium, and an assumed atmospheric pressure at the top of the saturated confined formation.

Table 2. Chemical Data of PCE and Capillary Data Used in the Simulations

\begin{tabular}{ll}
\hline Property & Value \\
\hline Water density & $1.00 \mathrm{~g} / \mathrm{cm}^{3}$ \\
PCE density & $1.63 \mathrm{~g} / \mathrm{cm}^{3}$ \\
Surfactant density & $1.15 \mathrm{~g} / \mathrm{cm}^{3}$ \\
Water viscosity & $1.00 \mathrm{cp}$ \\
PCE viscosity & $0.89 \mathrm{cp}$ \\
PCE/Water IFT & $45 \mathrm{dyn} / \mathrm{cm}$ \\
PCE solubility in water & $240 \mathrm{mg} / \mathrm{L}$ \\
PCE solubility in 4\% surfactant solution & $85,000 \mathrm{mg} / \mathrm{L}$ \\
Initial water saturation & 0.95 \\
Residual water saturation & 0.33 \\
Residual PCE saturation & 0.14 \\
\hline
\end{tabular}

\section{Model Results and Discussions}

The purpose of this study is to examine the capability of the presented model in simulating PCE contamination process and interpreting surfactant remediation effect. In order to achieve this goal, the total simulation period with a duration of 200 days is divided into three simulation phases: (i) day 0 day 30 PCE release phase; (ii) day 31 - day 100 PCE natural movement phase; and (iii) day 101 - day 200 surfactant-flushing remediation phase. The following are the detailed descriptions of modeling results in each simulation phase. 
Table 3. Model Discretization Parameters and Boundary and Initial Conditions

\begin{tabular}{ll}
\hline Simulation Conditions & Value \\
\hline Spatial discretization & $\Delta \mathrm{x}=1 \mathrm{~m}$ \\
& $\Delta \mathrm{y}=25 \mathrm{~m}$ \\
& $\Delta \mathrm{z}=1 \mathrm{~m}$ \\
& $\tilde{C}_{3}=0$ \\
& $\tilde{C}_{2}=0$ \\
Initial conditions & $\tilde{C}_{1}=1$ \\
& Impervious top \& bottom layer \\
Boundary conditions & No flow at top \& bottom layer \\
& Constant left \& right pressure \\
Source/Sinks & $1 \mathrm{~m}^{3} /$ day for 30 days \\
PCE spills & $70 \mathrm{~m}^{3} /$ day \\
Production well (1) & $35 \mathrm{~m}^{3} /$ day for each \\
Injection wells (2) &
\end{tabular}

\subsection{Day 0 - Day 30 PCE Release and Contamination Phase}

The first simulation phase represents the contamination event happened at the test site. A total of $30 \mathrm{~m}^{3}$ PCE is assumed to be released at a constant rate of $1.0 \mathrm{~m}^{3} /$ day for 30 days. In this simulation phase, PCE is released as a point pollution source in the center grid block at the top layer of the simulation aquifer.

After PCE is released into the aquifer, some would be dissolved into the groundwater, being as an aqueous phase. Overall PCE concentration in both aqueous and oleic phases (volume/volume on a total fluid basis) at various days during the 30-day release event is simulated and shown in Figure 2. The simulation results show that after 30-day release the PCE has reached the impervious lower boundary of the aquifer, and most of the PCE is trapped as a residual phase. The maximum lateral extent of the oleic PCE phase reaches about 5- $7 \mathrm{~m}$; while the maximum lateral extent of the dissolved PCE plume reaches about $18 \mathrm{~m}$. The spreading and movement of the released PCE in aquifer are due to the following driving forces: (i) gravity force; (ii) capillary pressure between the aqueous and organic PCE phases; (iii) natural hydraulic gradient from right to left across the simulated aquifer; and (iv) dissolution of the PCE in the water and its subsequent transport in the aqueous phase. After 30-day release of PCE, there is no PCE pool formed on the bottom layer of the aquifer.

\subsection{Day 31 - Day 100 PCE Natural Movement Phase}

The second phase simulation consists of a 70-day natural distribution period during which both production and injection wells are not operated. Under the natural hydraulic gradient condition and along with groundwater movement, the PCE movement would be either migrating downward through the aquifer formation, or becoming trapped by capillary forces as a residual phase. Meanwhile, more PCE would be dissolved in the contacting water and creating a contamination plume.

During this simulation phase, no more PCE is released and only groundwater flows through the aquifer domain for 70 days under natural gradient condition. The simulated PCE concentration at various time (volume/volume on a total fluid phase for both aqueous and oleic phases) is contoured and shown in Figure 3. It is indicated that further trapping and dispersion and spreading of the PCE occurs within this period. At day 100, the maximum lateral extent of the PCE plume has increased to $35-70 \mathrm{~m}$, moving toward the left hand boundary of the aquifer domain. A PCE pool has been formed and spread almost all over the bottom layer of the aquifer.

\subsection{Day 101 - Day 200 Surfactant-Flushing Remediation Phase}

In this simulation phase, surfactant solution is injected and modeled during the remediation of aquifer. Two remediation scenarios are considered (water-flooding and surfactant-flooding) for comparing remediation-enhancement effect created by the surfactant. For surfactant-flooding scenario, a $4 \%$ surfactant solution (in weight) is injected at a constant rate of $70 \mathrm{~m}^{3} /$ day throughout the cleanup period. Water-flooding scenario involves the same injection rate of water throughout the cleanup period.

Figure 4 shows the contour of simulated PCE concentration (volume/volume on a total fluid phase for both aqueous and oleic phases) at various time during the surfactant-flooding and remediation period. The location of injection-production well system is also presented in Figure 4. The production well is rightly installed at the location of the PCE release point with a constant production rate of $70 \mathrm{~m}^{3} /$ day. One surfactant injection well is located $25 \mathrm{~m}$ to the right of the production well, and the other surfactant injection well is located $36 \mathrm{~m}$ to the left of the production well. The injection rate for each injection well is $35 \mathrm{~m}^{3}$ /day for achieving a balance between the total injection and production rate. All the wells are screened over the entire $15 \mathrm{~m}$ vertical thickness of the aquifer. The criteria for locating the wells and designing pumping rates is for confining the PCE contamination plume during the remediation process and trying to capture all of the contaminated fluid within the aquifer domain. During the early surfactant-flooding period, the surfactant solution had not yet circulated throughout the domain. At this early time, the surfactant-enhanced solubility is not yet apparent and PCE removal is primarily due to free phase removal. Then at day 120 , there has been $40 \%$ PCE removed from the aquifer, indicating a significantly enhanced solubility and mobility of PCE in water. At day 200, almost 95\% of the PCE has been removed. After 300 days of injection and production, almost all of the PCE has been removed from the aquifer.

The same simulation is also conducted for water-flooding scenario with PCE removal rate presented in Table 4. Comparing with that under surfactant-flooding scenario, the removal rate under water-flooding scenario is too slow. At day 120 , only $1 \%$ of PCE is removed from the aquifer. At day 200, only $7 \%$ of PCE is removed from the aquifer. For removing all the PCE by using the water-flooding method, 30 years may be required. 

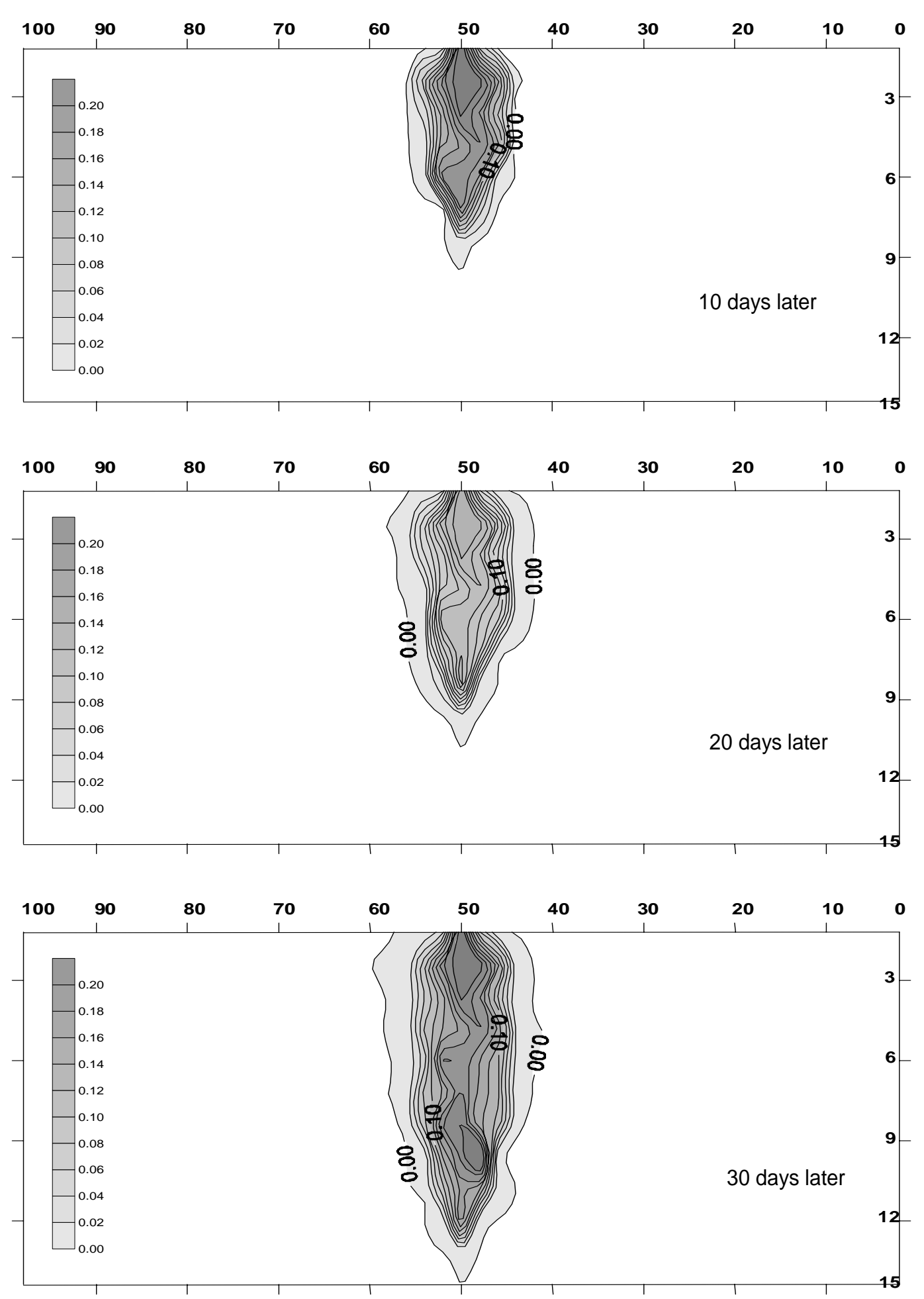

Figure 2. The simulated overall PCE concentrations in PCE release phase. 

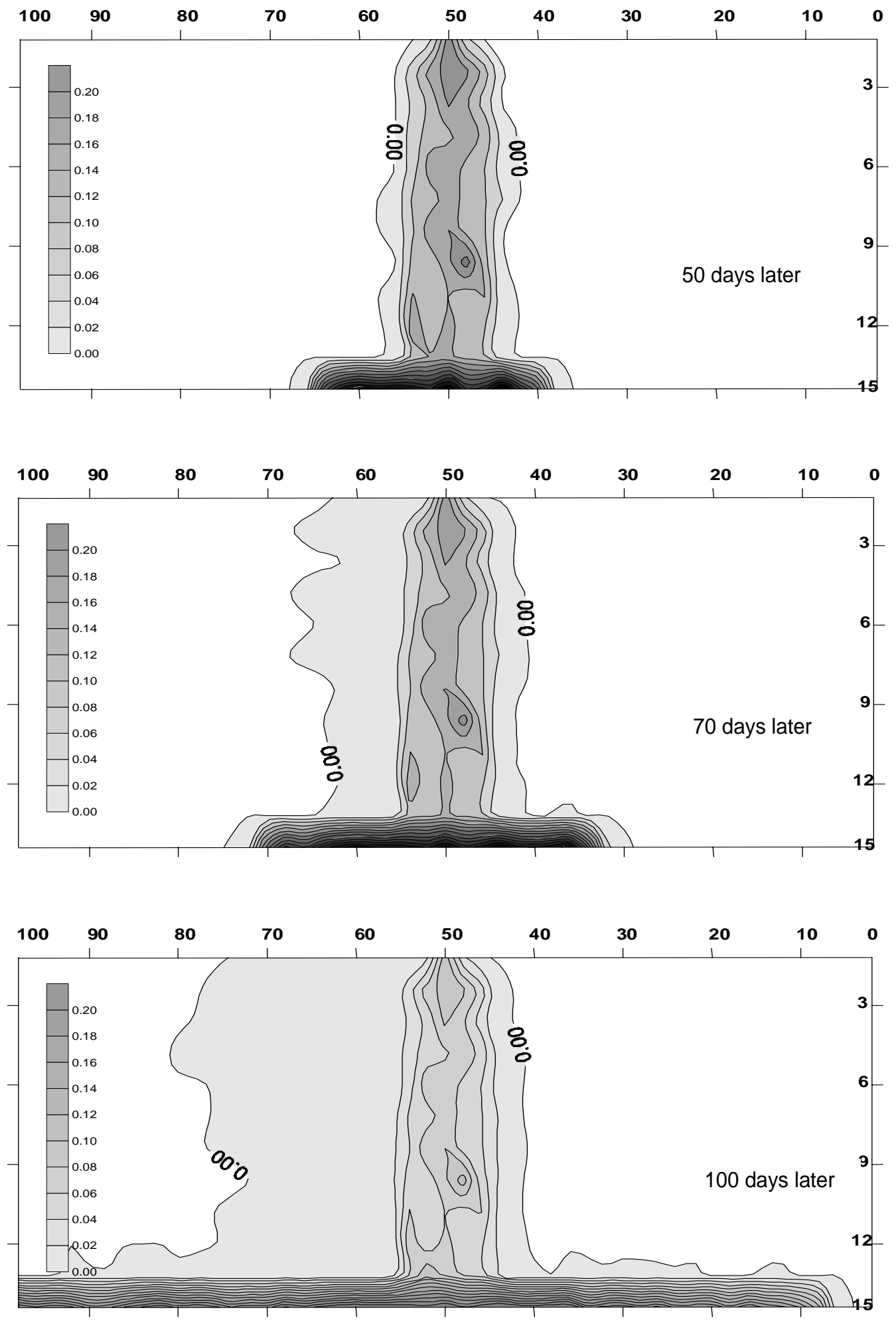

Figure 3. The simulated overall PCE concentrations during PCE natural movement phase. 

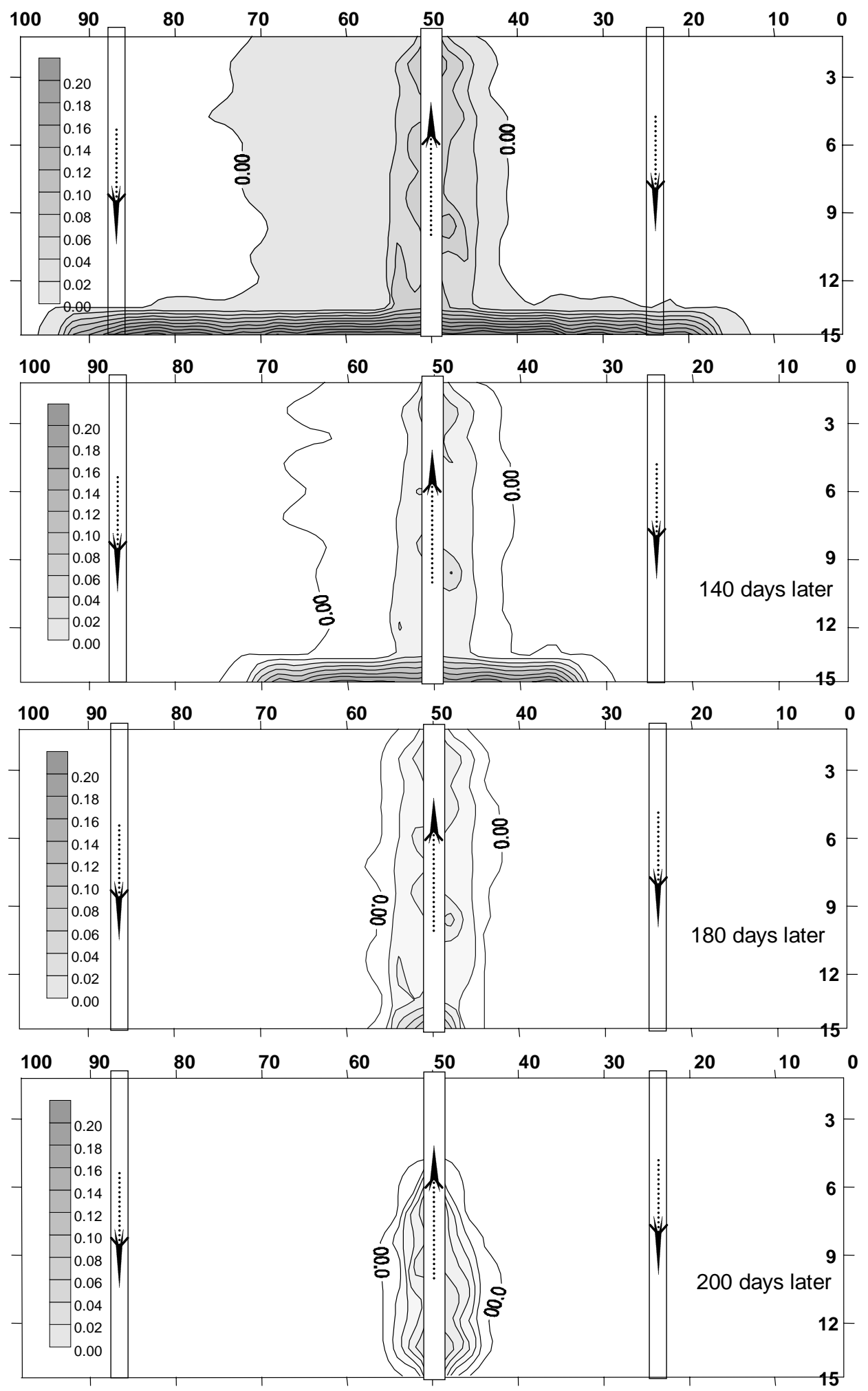

Figure 4. The simulated overall PCE concentrations during SEGR phase. 
The simulation results suggest that surfactant-enhanced groundwater remediation has the potential to cleanup the contaminated aquifer with improved cost-effectiveness and efficiencies. However, for applying this technology to real case studies, not only more factors should be considered such as natural biodegradation effect in subsurface, PCE sorption, but also experimental studies in both laboratory and pilot scale should be undertaken to further verify the numerical modeling results. Meanwhile, for practical implementation, the remediation design needs to consider the cleanup of the remaining surfactant in aquifer as well as surfactant recovery from the produced water.

\section{Conclusions}

This study reports a numerical approach for simulation of surfactant-enhanced aquifer remediation and the simulation results from the test site have provided comprehensive insights into the remediation process. The remediation process is affected by many factors, such as aquifer properties, chemical characteristics of contaminant, and surfactant chemistry. Multi-phases are very important in the transport and fate of NAPL and should be reflected in the mathematical models. The simulation results indicate that the surfactant has the significant potential to improve remediation efficiency, reduce remediation time, and lower down remediation costs in comparison with conventional pump-and-treat remediation measure. This result could strongly support the application of surfactant-enhanced technologies to real-world problems.

The preliminary scoping simulations presented in this study demonstrate the capability of the proposed model in simulating the surfactant-enhanced remediation of a DNAPLcontaminated site and interpreting surfactant enhancement effect. The simulation results have implications regarding the utilization of the proposed method for typical site remediation problems. In most cases, there will not be enough physical data available to simulate PCE (or other NAPL) migration. However, given some approximate knowledge of initial PCE distribution and layering, surfactant-enhanced remediation can be simulated with a reasonable degree of certainty. Therefore, the mathematical modeling method can be useful for examining remediation alternatives, optimal surfactant properties (solubility, mobility), pumping schemes, and DNAPL recovery. In the future studies for practical application, parameter sensitivity simulations should be undertaken for identifying which parameters have a significant impact on simulation results. The most sensitive parameters must be well considered and designed for field application.

Acknowledgments. This research has been supported by the Natural Sciences and Engineering Research Council of Canada. The author thanks the anonymous reviewers for their comments and suggestions that are helpful in improving the manuscript.

\section{References}

Abriola, L.M. and Pinder, G.F. (1989). Modeling multiphase migration of organic chemicals in groundwater systems-A review and assessment. Environ. Health Persp., 83, 117-143.

Abriola, L.M. and Pinder, G.F. (1985a). A multiphase approach to the modeling of porous media contamination by organic compounds, 1. Equation development. Water Resour. Res., 21(1), 11-18.

Abriola, L.M. and Pinder, G.F. (1985b). A multiphase approach to the modeling of porous media contamination by organic compounds: 2. Numerical simulation. Water Resour. Res., 21(1), 19-26.

Abriola, L.M., Dekker, T.J. and Pennell, K.D. (1993). Surfactant enhanced solubilization of residual dodecane in soil columns, 2, Mathematical modeling. Environ. Sci. Technol., 27(12), 2341-2351.

Babu, D.K. and Odeh, A.S. (1989). Productivity of horizontal well. SPE Reserv. Eng., 4, 417-421.

Bear, J. (1979). Hydraulics of Ground Water, McGraw-Hill, New York

Bhuyan, D., Pope, G.A. and Lake, L.W. (1990). Mathematical modeling of high-pH chemical flooding. SPE Reserv. Eng., 5(2), 213.

Brown, C.L., Pope, G.A., Abriola, L.M. and Sepehrnoori, K. (1994). Simulation of surfactant enhanced aquifer remediation. Water Resour. Res., 30(11), 2959-2978.

Corapcioglu, M.Y. and Baehr, A.L. (1987). A compositional multiphase model for groundwater contamination by petroleum products: 1. Theoretical considerations. Water Resour. Res., 23(1), 191-200.

Datta Gupta, A., Pope, G.A., Sepehronoori, K. and Thrasher, R.L. (1986). A symmetric, positive definite formulation of a three-dimensional micellar/polymer simulator. SPE Reserv. Eng., 1(6), 622-632.

De Blanc, P.C. (1996). Development and Demonstration of a Biodegradation Model for Non-Aqueous Phase Liquids in Groundwater, Ph.D. dissertation, The University of Texas at Austin.

Delshad, M. and Pope, G.A. (1989). Comparison of the three-phase oil relative permeability models. Transp. Porous Media, 4(1), 59-83.

Delshad, M., Pope, G.A. and Sepehrnoori, K. (1996). A compositional simulator for modeling surfactant enhanced aquifer remediation, 1. Formulation. J. Contam. Hydrol., 23, 303-327.

Faust, C.R. (1985). Transport of immiscible fluids within and below the unsaturated zone: a numerical model. Water Resour. Res., 21(4), 587-597.

Faust, C.R., et al. (1989). Simulation of three-dimensional flow of immiscible fluids within and below the unsaturated zone. Water Resour. Res., 25(12), 2449-2464.

Falta, R.W. Pruess, K., Javandel, I. and Witherspoon, P.A. (1992a). Numerical modeling of steam injection for the removal of nonaqueous phase liquids from the subsurface, 1 . Numerical formulation. Water Resour. Res., 28(2), 433-449.

Falta, R.W., Pruess, K., Javandel, I. and Witherspoon, P.A. (1992b). Numerical modeling of steam injection for the removal of nonaqueous phase liquids from the subsurface, 2 . Code validation and application. Water Resour. Res., 28(2), 451-465.

Fountain, J.C. and Hodge, D.S. (1992). Extraction of organic pollutants using enhanced surfactant flushing-initial field test (part 1), Project summary, New York State Center for Hazardous Waste management, State University of New York at Buffalo.

Fountain, J.C., Starr, R.C., Middleton, T., Beikirch, M., Taylor, C. and Hodge, D. (1997). A controlled field test of surfactant-enhanced aquifer remediation. Groundwater, 34, 910-916.

Haley, J.L., Hanson, B., Enfield, C. and Glass, J. (1991). Evaluating the effectiveness of ground water extraction systems. Ground Water Monit. Rev., 111(3), 119-124.

Huyakorn, P.S., Wu, Y.S. and Panday, S. (1994). A comprehensive three-dimensional numerical model for predicting the fate of petroleum hydrocarbons in the subsurface, in Proc. Conf. on Petroleum Hydrocarbons and Organic Chemicals in Ground 
Water: Prevention, Detection, and Restoration, Natl Ground Water Assoc., Dublin, OH, pp. 239-253.

Kaluarachchi, J.J. and Parker, J.C. (1989). Modeling multicomponent organic chemical transport in three-fluid-phase porous media. $J$. Contam. Hydrol., 5, 349-374.

Katyal, A.K. (1997). BIOF\&T flow and transport in the saturated and unsaturated zones in 2- or 3-dimensions: technical document \& user guide, Draper Aden Environmental Modeling, Inc., Blacksburg, VA.

Kueper, B.H. and Frind, E.O. (1991). Two-phase flow in heterogeneous porous media, 1, Model development. Water Resour. Res., 27(6), 1049-1057.

Kuppasamy, T., Sheng, J., Parker, J.C. and Lenhard, R.J. (1987) Finite element analysis of multiphase immiscible flow through soils. Water Resour. Res., 23(4), 625-631.

Liu, J. (1993). High-Resolution methods for Enhanced Oil Recovery Simulation, Ph.D. dissertation, The University of Texas, Austin.

Mackay, D.M. and Cherry, J.A. (1989). Groundwater contamination: pump and treat remediation. Environ. Sci. Technol., 23(6), 630-636.

Mason, A.R. and Kueper, B.H. (1996). Numerical simulation of surfactant flooding to remove pooled DNAPL from porous media. Environ. Sci. Technol., 30(11), 3205-3215.

NRC (the National Research Council) (1994). Alternatives for Groundwater Cleanup, National Academy Press, Washington, DC.

Panday, S., Forsyth, P.A., Falta, R.W., Wu, Y.S. and Huyakorn, P.S. (1995). Consideration for robust compositional simulations of subsurface nonaqueous phase liquid contamination and remediation. Water Resour. Res., 31(5), 1273-1289.

Peaceman, D.W. (1983). Interpretation of well-block pressures in numerical reservoir simulation with nonsquare gridblocks and anisotropic permeability. SPE J., 23(3), 531-543.

Pennell, K.D., Pope, G.A. and Abriola, L.M. (1994). Surfactant enhanced remediation of soil columns contaminated by residual tetrachloroethylene. J. Contam. Hydrol. 16, 35-53.

Pennell, K.D. and Abriola, L.M. (1997). Surfactant enhanced aquifer remediation: fundamental processes and practical application, in S.K. Sikdar and R.L. Irvine (Eds.), Bioremediation: Principles and Practice, Vol. 1. Technomic Publ., Lancaster, PA, pp. 693-750.

Saad, N., Pope, G.A. and Sepehrnoorl, K. (1990). Application of higher-order methods in compositional simulation. SPE Reserv. Eng., 5(4), 623-633.

USEPA (1991). Arid, Water Reclamation Reuse Guidelines.

USEPA (1996). Innovative treatment technologies: Annual status report ( $8{ }^{\text {th }}$ Ed.), Office of Solid Waste and Emergency Response, EPA-542-R-96-010 No. 8.

USGS (1990). National Water Summary 1987-Hydrologic Events and Water Supply and U.S. Geological Survey Water-Supply Paper, 2350: 553.

Wang, P. and Barker, J.W. (1997). Comparison of flash calculations for IMPES compositional reservoir simulators. In-situ, 21(3), 223-237.

West, C.C. and Harwell, J.H. (1992). Surfactants and subsurface remediation. Environ. Sci. Technol. 26(12), 2324-2330.

Wilson, D.J. (1989). Soil clean up by in-situ surfactant flushing, 1, Mathematical modeling. Sep. Sci. Technol., 24, 863-892.

Wilson, D.J. and Clarke, A.N. (1991). Soil clean up by in-situ surfactant flushing, IV, A two-compnent mathematical mode. Sep. Sci. Technol., 26, 1177-1194. 